\title{
脳血管障害による嚥下運動障害者の嚥下障害重症度変化と嚥下運動指標 および頸部・体幹機能との関連性
}

\author{
吉田 剛 ${ }^{122}$ 内山 靖2)
}

\begin{abstract}
要 約 目的：脳血管障害 (CVD) による讌下運動障害者の讌下障害重症度が変化したときの讌下運動お よび頸部・体幹機能の変化の関連性を検証して, 臨床上注目すべきポイントを明らかにすること. 方法：対 象は, 2 週間以上の間隔をあけて 2 回以上の測定を行ったCVDによる曣下運動障害者 59 例で, 嚥下障害重 症度の変化から $\mathrm{A}$ ：改善群， B : 悪化群, $\mathrm{C}$ : 不変群の 3 群に分類した。曣下障害重症度は, 4 つの燕下機 能評価（反復唾液嚥下テスト, 改訂版水飲みテスト, 食物テスト, 才藤の臨床的病態重症度）とし, このう ちのいずれかの 1 ランク以上の変化を改善または悪化の判断基準とした. 嚥下運動および頸部・体幹機能は, 筆者らが開発した 4 つの嚥下運動指標（オトガイ〜甲状軟骨間距離 GT・甲状軟骨〜胸骨間距離 TS・相対

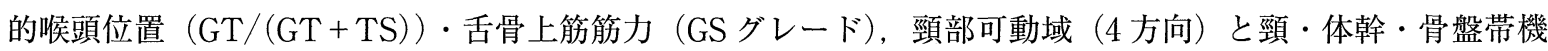
能ステージ（NTP ステージ）の計 9 項目であった．変化した前後の各指標の比較には Wilcoxon の符号付順 位和検定を用い, 危険率 $5 \%$ 未満を有意水準とした。結果 : A 群は 30 例 (平均 68.1 歳), B 群は 6 例（平 均 78.7 歳), $\mathrm{C}$ 群は 23 例（平均 73.0 歳）であった. 各群間の基礎デー夕には有意差がなく, 変化前の機能 は, $\mathrm{B}$ 群の頸部回旋と側屈の可動域が $\mathrm{A}$ 群に比べ有意に低かった，與下運動の指標は， A 群では, 頸部伸 展と回旋可動域, GS グレード, NTP ステージの 4 つの指標が有意に改善した. B 群では相対的渎頭位置の み高位に変化した，C群では有意な変化はなかった，結論：嚥下機能の改善を図るには，嚥下筋機能 (局所) と頸部・体幹機能（全身）の両面からのアプローチが必要である．また，悪化を防ぐためには，不良姿勢な どに起因する喉頭位置の偏倚に注目したアプローチが必要である.
\end{abstract}

Key words : 嚥下, 讌下障害, 脳血管障害, 曣下機能, 運動機能

（日老医誌 $2006 ； 43 ： 755-760$ )

\section{緒言}

脳血管障害 (cerebral vascular disease : 以下, CVD)

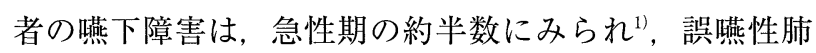
炎を招くことで, 早期リハビリテーションを阻害し, 生 命の危険をも脅かすため, それに対する取り組みは重要 である，鱟下障害を引き起こす原因は，嚥下中枢の障害 による球麻疩や両側性障害による偽性球麻痺が代表的で あるが，一側性障害によっても鱟下障害が生じることが 報告されている2)。また, 鱟下器官の運動障害によるも のだけでなく, 意識障害や高次神経障害, 感覚障害など によっても摂食・讌下障害が生じるが，嶼下運動障害の 発生頻度は嚥下障害に占める割合が比較的高く ${ }^{3)}$, 運動 療法の効果が期待できる.この研究では, 理学療法の対

1) T. Yoshida：本島総合病院リハビリテーション科

2) T. Yoshida, Y. Uchiyama: 群馬大学大学院医学系研 究科保健学専攻

受付日：2006.3.17, 採用日：2006.6.13
象として，特に外部からも評価・介入が可能な喉頭運動 を中心とした嚥下運動障害のみを取り上げて検討した。

嚥下時の喉頭の前上方挙上運動は，喉頭蓋閉鎖による 気道保護および食道入口部開大に必要な運動であり, 舌 骨上筋群であるオトガイ舌骨筋, 顎舌骨筋, 顎二腹筋前 腹などが舌骨挙上の, 甲状舌骨筋が甲状軟骨挙上の主動 作筋である ${ }^{4}$. 拮抗筋である舌骨下筋群 (甲状舌骨筋を 除く）拉よび胸骨甲状筋は，下方からこの運動の制御に 働いている.これらの拮抗筋群は, 胸骨・鎖骨・肩甲骨 などに付着しているため, 付着部の骨の位置関係による 影響を受けやすい，また，姿勢保持能力の低下による座 位姿勢時の頸部・体幹筋群の過活動, および呼吸状態不 良による呼吸補助筋の過活動により, 舌骨下筋群に運動 連鎖が生じることで，喉頭挙上運動を阻害しやすい状態 になることも考えられる．

高齢者の場合, 舌骨下筋群が短縮し, 喉頭位置が下制 する傾向があるため ${ }^{5}$, 喉頭運動開始位置が低くなるこ とで，曣下運動がタイミングよく十分に行えない可能性 
表 1 全対象者および各群の基礎データ

\begin{tabular}{|c|c|c|c|c|c|c|c|c|}
\hline & & 全対象者 & 改善群 & 悪化群 & 不変群 & $\mathrm{p}$ 值 & 有意差 & 多重比較 \\
\hline \multirow{2}{*}{\multicolumn{2}{|c|}{$\begin{array}{l}\text { 年齢（歳） } \\
\mathrm{n} \text { （性別：男性／女性） }\end{array}$}} & $71.1 \pm 13.8$ & $68.1 \pm 14.8$ & $78.7 \pm 3.4$ & $73.0 \pm 13.2$ & 0.157 & n.s. & n.s. \\
\hline & & $59(35 / 24)$ & $30(18 / 12)$ & $6(4 / 2)$ & $23(13 / 10)$ & 0.898 & n.s. & n.s. \\
\hline \multicolumn{2}{|c|}{ 発症からの期間（日） } & $122.8 \pm 354.8$ & $67.2 \pm 69.9$ & $274.3 \pm 211.9$ & $155.8 \pm 551.0$ & 0.369 & n.s. & n.s. \\
\hline \multicolumn{2}{|l|}{ 検査間日数（日） } & $34.6 \pm 21.8$ & $29.4 \pm 15.6$ & $46.7 \pm 14.9$ & $38.3 \pm 28.1$ & 0.121 & n.s. & n.s. \\
\hline \multirow[t]{3}{*}{ 病型（人数） } & 脳梗塞 & 45 & 24 & 5 & 16 & 0.662 & n.s. & n.s. \\
\hline & 脳出血 & 13 & 5 & 1 & 7 & & & \\
\hline & くも膜下出血 & 1 & 1 & 0 & 0 & & & \\
\hline \multirow[t]{4}{*}{ 麻痺側（人数） } & 右 & 18 & 8 & 3 & 7 & 0.344 & n.s. & n.s. \\
\hline & 左 & 29 & 12 & 3 & 14 & & & \\
\hline & 両側 & 7 & 5 & 0 & 2 & & & \\
\hline & なし & 5 & 5 & 0 & 0 & & & \\
\hline \multirow[t]{3}{*}{ 病巣部位（人数） } & 一側 & 29 & 12 & 4 & 13 & 0.190 & n.s. & n.s. \\
\hline & 脳幹 & 16 & 7 & 2 & 7 & & & \\
\hline & 両側 & 14 & 11 & 0 & 3 & & & \\
\hline
\end{tabular}

年齢・発症からの期間・検查間日数：一元配置分散分析および Bonferroni の不等式を用いた多重比較検定 $(\mathrm{p}<0.05)$

それ以外の項目 $: \chi^{2}$ 検定 $(\mathrm{p}<0.05)$

表 2 改訂版水のみテスト (MWST) と食物テスト (FT) の判定基準（文献 9 より引用）

1：嚥下なし, むせる and/or 呼吸切迫

2 : 燕下あり, 呼吸切迫 (silent aspiration)

3 ：嚥下あり, 呼吸良好, むせる and/or 湿性嗄声 and/or 口腔 内貯留中等度

4：嚥下あり，呼吸良好，むせない

$5: 4$ に加え, 追加嚥下運動が 30 秒以内に 2 回可能

注：MWST は冷水 $3 \mathrm{ml}, \mathrm{FT}$ はプリンまたはゼリー $4 \mathrm{~g}$ を口腔 前庭に入れて嚥下させ, 可能な場合はさらに 2 試行追加し, 最も悪い結果を評価した

が高くなる。

Stambolis らは, 健常若年者に頸椎装具を装着し，ビ

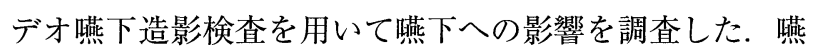
下時に必要なわずかな頸椎の運動を阻害するだけで, $82 \%$ に何らかの燕下への影響が見られたと報告してい $ろ^{6}$.

CVD による片麻疩者の場合は, 球麻疩や偽性球麻疩 がなくても，運動麻痺による姿勢保持能力の低下とそれ に伴う異常姿勢や頸部筋の筋緊張異常などの影響で嚥下 運動が阻害されやすい状態になることは容易に想像でき る.

嚥下障害を経時的に追跡した研究では, 発症から 2 週 間から 1 力月程度で燕下障害が消失するケースがあると いう一過性障害についての報告 ${ }^{788}$ があり, 自然回復する ものは対象から除外する必要性があることを示唆してい る. しかし, 縦断研究の報告は少なく, 苝下障害の変化 と同期して生じる運動機能の変化に注目した縦断研究は 見当たらない.
これまで筆者らは，これらの讌下運動阻害因子につい ての指標を開発し, 頸部可動性や舌骨上筋群の機能が苝 下運動に影響を与えていることを報告した5).

今回我々は, これらの指標を用いて, CVDの觾下運 動障害者の噁下障害重症度が変化するときに, 同時にど の運動機能が変化しているかを検証することで，どの因 子が與下運動の変化に影響を与えているかを明らかにし ようと試みた。これにより，嚥下障害の改善のためのア プローチを行ううえで注目すべき機能や視点，および輿 下機能を悪化させないよう維持するうえで注目すべき機 能や視点を抽出することが期待できる.

\section{方 法}

1. 対象

$\mathrm{M}$ 病院に捛いて 2 週間以上の間隔をあけて 2 回以上 の測定を行うことができたCVDによる嚥下運動障害患 者 59 例（平均年齢 $71.1 \pm 13.2$ 歳, 男女比 $35 ： 24$ ）を対 象とした。病型，麻瘇側および病巣部位の内訳は表 1 に 示したとおりである，対象者は，経過観察中の曣下障害 重症度の変化により改善群, 悪化群, 不変群の 3 群に分 類した.

燕下障害重症度は, 以下の 4 つの嚥下機能評価 (表 2 , 3 参照）を用い，嚥下物毎の燕下状態を評価できる反復 唾液燕下テスト（repetitive saliva swallowing test：以 下 RSST) ${ }^{9}$, 改訂版水飲みテスト (modified water swallowing test: 以下 MWST) ${ }^{10)}$, 食物テス卜 (food test : 以下 $\mathrm{FT})^{10)}$ と, 才藤らの燕下障害の臨床的病態重症度分 類 (Saitoh's classification : 以下 class) ${ }^{11}$ とし，このうち のいずれかの 1 ランク以上の変化を改善または悪化の判 
表 3 才藤の摂食・䁵下障害の臨床的病態重症度に関する分類（文献 9 より一部改変）

$7:$ 正常範囲：摂食・噁燕下に問題なし. 嚥下訓練の必要なし.

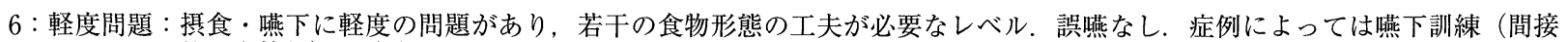
的・直接的）の適応.

5 : 口腔問題 : 主に準備期や口腔期の中等度から重度の障害があるもの. 咀嚼に対して食物形態の工夫が必要. 誤讌なし. 嚥下訓練 (間接的・直接的) の適応.

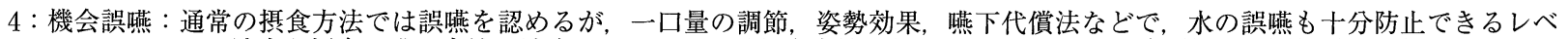
ル。適当な摂食・嚥下方法が適応されれば，医学的安定性は保たれる。曣下訓練（間接的・直接的）の適応。

$3:$ 水分誤嚥 : 水の誤嚥を認め, 誤嚥防止法の効果は不十分であるが, 食物形態効果は十分に認めるレベル。嚥下食が選択される. 適当な摂食・黇下方法が適応されれば，医学的安定性は保たれる。嚥下訓練（間接的・直接的）の適応.

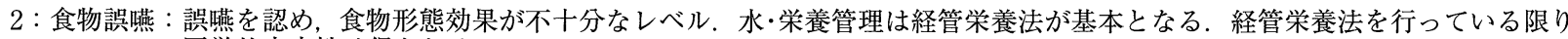
医学的安定性は保たれる。 間接的訓練の適応. 直接的訓練は専門施設で施行.

$1 ：$ 唾液誤嚥：常に唾液も誤嚥していると考えられるレベル，持続的な経管栄養法を必要とするが, 誤嚥のために医学的安定性を保 つことが困難. 合併症のリスクが高く, 直接的訓練も施行が困難なレベル。

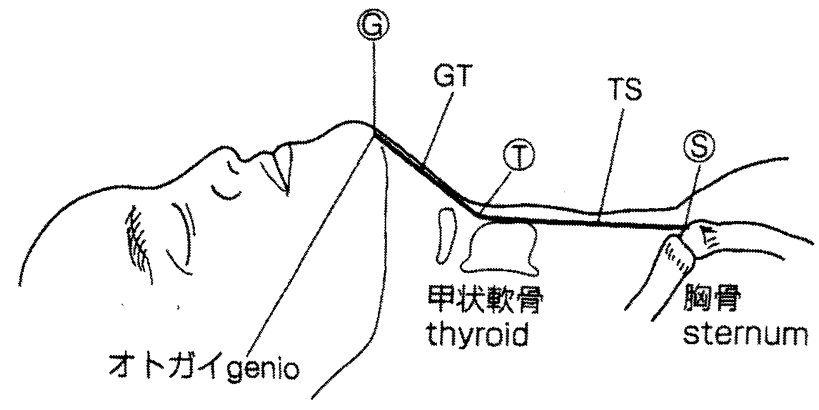

図 $1 \mathrm{GT}$ ・ TS の測定方法

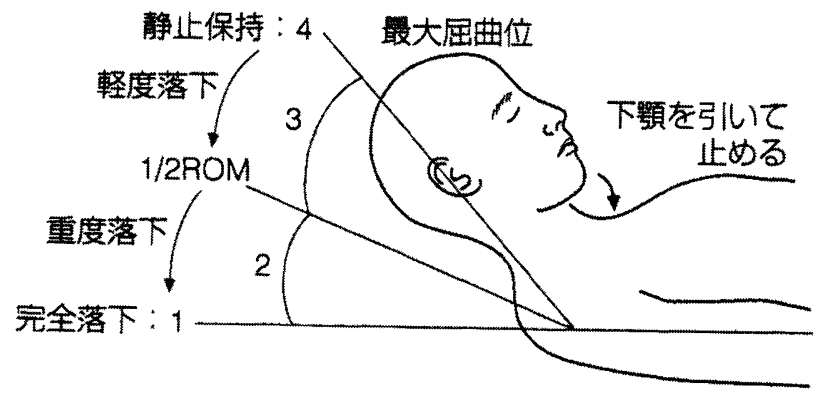

図 2 GS グレードの測定方法

表 4 各群の変化前の状況

\begin{tabular}{|c|c|c|c|c|c|c|c|}
\hline & & $\begin{array}{c}\text { 改善群 a) } \\
(\mathrm{n}=30)\end{array}$ & $\begin{array}{c}\text { 悪化群 b) } \\
(\mathrm{n}=6)\end{array}$ & $\begin{array}{l}\text { 不変群 } \mathrm{c}) \\
(\mathrm{n}=23)\end{array}$ & $\mathrm{p}$ 值 & 有意差 & 多重比較 \\
\hline \multicolumn{8}{|l|}{ 嶼下障害重症度 } \\
\hline RSST & & $1.8 \pm 1.3$ & $1.3 \pm 1.2$ & $1.5 \pm 1.6$ & 0.609 & n.s. & n.s. \\
\hline MWST & & $3.3 \pm 1.0$ & $3.3 \pm 0.5$ & $3.3 \pm 1.2$ & 0.547 & n.s. & n.s. \\
\hline FT & & $3.6 \pm 1.0$ & $4.0 \pm 0.0$ & $3.5 \pm 1.2$ & 0.600 & n.s. & n.s. \\
\hline Class & & $3.1 \pm 1.1$ & $3.3 \pm 0.8$ & $3.7 \pm 1.8$ & 0.355 & n.s. & n.s. \\
\hline \multicolumn{8}{|l|}{ 曣下運動指標 } \\
\hline GT & & $5.4 \pm 1.2$ & $4.7 \pm 0.9$ & $5.7 \pm 1.4$ & 0.175 & n.s. & n.s. \\
\hline TS & & $8.8 \pm 1.4$ & $7.4 \pm 1.9$ & $8.2 \pm 1.0$ & 0.040 & $*$ & n.s. \\
\hline $\mathrm{T}$ 位置 & & $0.38 \pm 0.05$ & $0.39 \pm 0.03$ & $0.41 \pm 0.05$ & 0.115 & n.s. & n.s. \\
\hline GS グレード & & $2.8 \pm 1.4$ & $2.0 \pm 1.3$ & $2.5 \pm 1.4$ & 0.434 & n.s. & n.s. \\
\hline \multicolumn{8}{|l|}{ 頸部·体幹機能 } \\
\hline NTP ステー & & $3.0 \pm 1.8$ & $1.3 \pm 0.8$ & $2.5 \pm 1.9$ & 0.063 & n.s. & n.s. \\
\hline \multirow[t]{4}{*}{ 頸部可動域 } & 屈曲 & $38.0 \pm 12.6$ & $35.8 \pm 12.8$ & $36.1 \pm 16.6$ & 0.870 & n.s. & n.s. \\
\hline & 伸展 & $38.8 \pm 11.8$ & $28.3 \pm 7.5$ & $39.6 \pm 14.2$ & 0.140 & n.s. & n.s. \\
\hline & 回旋 & $48.8 \pm 16.6$ & $26.7 \pm 15.1$ & $42.2 \pm 14.6$ & 0.008 & $* *$ & a) $* *$ b) \\
\hline & 側屈 & $28.8 \pm 12.1$ & $14.2 \pm 4.9$ & $27.2 \pm 13.5$ & 0.033 & * & a) $*$ b) \\
\hline
\end{tabular}

RSST, MWST, FT, GS グレード, NTP ステージ : Kruskal-Wallis 検定 $(*: p<0.05)$

GT, TS, T 位置, 頸部可動域 : 一元配置分散分析 $(\mathrm{p}<0.05, * *: \mathrm{p}<0.01)$

多重比較：Bonferroni の不等式による多重比較検定（p<0.05，＊*: p < 0.01）

RSST; repetitive saliva swallowing test, MWST; modified water swallowing test, FT; food test, Class;Saitoh's classification, GT ; genion-thyroid distance, TS ; thyroid-sternum distance, T 位置 ; thyroid position, GS グレード ; genionsterunum grade, NTP ステージ; neck-trunk-pelvis stage 
表 5 各群の指標変化の結果

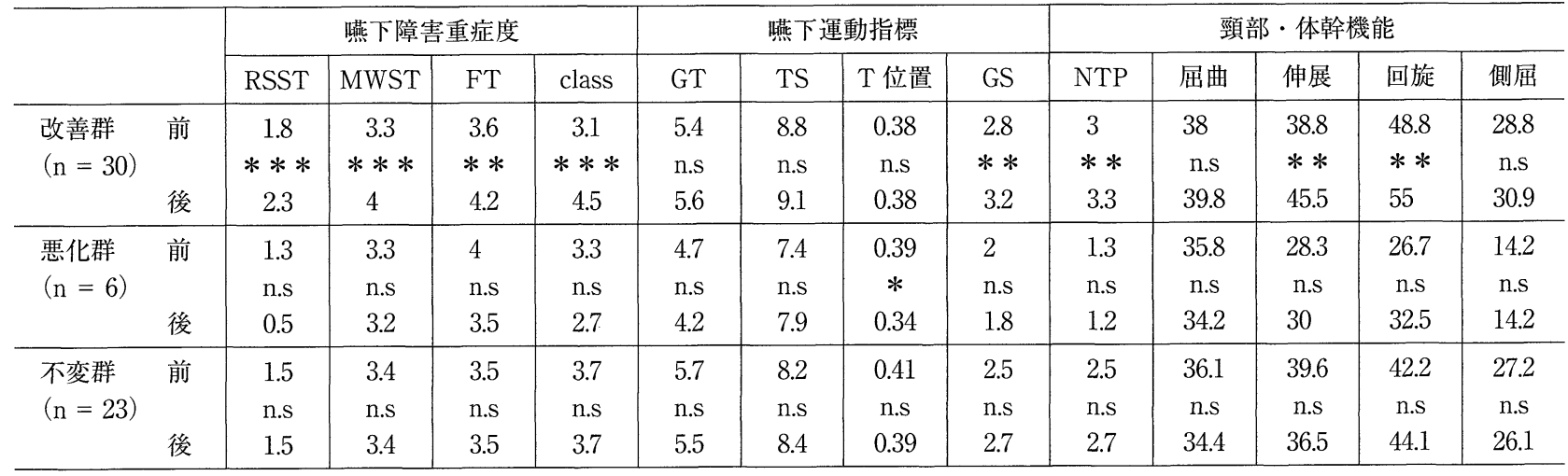

Wilcoxon の順位和検定 : $* * *: \mathrm{p}<0.001, * *: \mathrm{p}<0.01$, $*: \mathrm{p}<0.05$, n.s : not significant

RSST ; repetitive saliva swallowing test, MWST ; modified water swallowing test, FT ; food test, Class ; Saitoh's classification GT ; genion-thyroid distance, TS ; thyroid-sternum distance, T 位置 ; thyroid position, GS ; genion-sterunum grade

NTP ; neck-trunk-pelvis stage

断基準とした.

燕下運動障害の判定方法は, 舌, 喉頭, 軟口蓋などの 運動機能障害があり，かつ才藤らの臨床的病態重症度分 類で 6 以下の與下障害を有するものとした．この際，1 カ月以内に讌下障害が消失する一過性障害者㧍よび意識 障害や高次神経障害, 感覚障害が主原因であると考えら れる勳下障害者は除外した。

全ての対象者は，理学療法と言語聴覚療法を実施され ており, 必要に応じて燕下障害へのアプローチが行われ ていた．また，事前に十分な説明を口頭で行い，同意を 得たうえで研究の対象とした。

\section{2. 帰結評価}

測定項目は, 開発した 4 つの曣下運動指標であるオト ガイ〜甲状切痕間距離 (genion-thyroid distance：GT), 甲状切痕～胸骨上切痕間距離（thyroid-sternum distance : TS), 相対的喉頭位置 (relative thyroid position : $\mathrm{T}$-position $=\mathrm{GT} /(\mathrm{GT}+\mathrm{TS}))$, 舌骨上筋機能グレード $(\mathrm{GS}$ grade $)^{5)}$ と, 頸部・体幹機能として吉尾らの頸・体幹・ 骨盤帯機能ステージ (neck-trunk-pelvis stage : NTP ス テージ ${ }^{12}$ ， および頸部周囲筋の筋緊張を表す頸部可動 域（neck range of motion：以下，頸部 ROM） 4 方向の 計 9 項目であった.

GT およびTSの測定は，側臥位で頸部最大伸展位を とり,テープメジャーを用いて $5 \mathrm{~mm}$ 単位で計測した(図 1 参照). GS グレードは, 背臥位で他動的に最大頸部屈 曲位をとらせ，顎を引いて頭部挙上位を保持するよう指 示したうえで頭部の支えを外し，頭部が落下する程度を 図 2 に示す 4 段階に分けて測定した。 なお，GT, TS, GS グレードについては, 計測精度と再現性について検
証済みである5．頸部 ROM の測定は，1995 年に日本整 形外科学会と日本リハビリテーション医学会が改訂した 方法に準拠して，軸心，基本軸，移動軸を設定した．全 測定は，臥位で行い，伸展は側卧位，その他は背臥位で 行った。自作の角度板を用いて他動的可動域を測定し， 回旋と側屈は制限側の值を採用した。

\section{3. 解析方法}

群間比較のうち男女比, 病型, 麻瘏側, 病巣部位など の名義尺度デー夕については， $\chi^{2}$ 検定（クロス集計表） を, RSST, MWST, FT, Class, GSグレード, NTP ステージなどの順序尺度データについては, KruskalWallis 検定および Bonferroni の不等式による多重比較 検定を, 年齢, 発症日数, 検査日数, GT, TS, T 位置, 頸部可動域などの間隔・比率尺度デー夕については，一 元配置分散分析および Bonferroni の不等式による多重 比較検定を行った。

群内比較のうち改善群と悪化群については, 変化が生 じた前後の 2 デー夕を, 不変群については, 変化した群 の平均日数に近い初回デー夕と約 1 カ月後のデータを分 析した．変化した前後の各指標の比較にはWilcoxonの 符号付順位和検定を用いた．全ての検定は，危険率 5\% 未満を有意水準とした。

\section{結 果}

1. 群分け結果（当院における嚥下治療成績：表 1）

與下機能に変化がみられた前後の検査間日数は平均 32.3 日（改善群: 29.4 日, 悪化群 : 46.7 日), 不変群の 検查間日数は平均 38.3 日であった，対象者 59 例の分布 は, 改善群が 30 例 $(51.0 \%$ : 平均年齢 $68.1 \pm 14.8$ 歳), 
悪化群が 6 例（10.2\%：平均年齢 $78.7 \pm 3.4$ 歳）, 不変群 が 23 例（38.8\%：平均年齢 $73.0 \pm 13.2$ 歳）であった.

2. 群間比較（表 1,4 ）

各群間には, 病型, 麻痺側, 病巣部位, 平均年齢, 性 別, 発症からの期間などの基本情報に関して, 有意差は みられなかった，また, 変化前の機能を比較すると, 改 善群に比べて悪化群では, 頸部回旋・側屈可動域が有意 に低かった。

\section{3. 群内比較 (表 5)}

嚥下運動の指標は, 改善群では, 頸部伸展と回旋可動 域，GS グレード，NTP ステージの 4 つが有意に改善し た．悪化群では喉頭位置のみ高位に偏倚するという変化 がみられた，不変群では有意な指標変化がみられなかっ た.

\section{考察}

1. 改善群の機能変化

改善群では, 頸部伸展や回旋の可動性が改善したこと が喉頭運動に関与する前頸筋群の伸張性につながり，嚥 下の局所機能である舌骨上筋の活動と, 全身機能である 頸部・体幹機能の改善が同時に生じることで與下運動が 改善したと考えられた。この結果は，曣下筋機能などの 局所機能の改善は, 座位姿勢保持に関わる体幹機能など の全身機能の改善によって準備されるのではないかとい う筆者らの仮説を間接的に証明しているといえる。この ことから，㝶下筋へのアプローチおよび與下時の姿勢効 果を期待した代償的方法などを単体で用いて改善を図る よりも，座位姿勢へのアプローチを通して頸部・体幹機 能の向上を図りながら, 嚥下筋の活動しやすい状況を準 備したうえで, 実際の與下活動へのアプローチを行うと いった構造的アプローチを用いる方が，嚥下障害の改善 に有効であると考える.

2. 悪化群の機能変化

今回の研究では, 悪化群の機能変化は喉頭位置の上方 偏倚のみであった。これまで, 加龄により喉頭位置が下 制することで，喉頭挙上が不十分となり嚥下障害が生じ

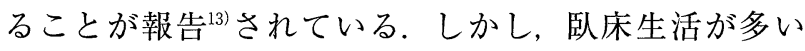
CVD 患者では，逆に喉頭が高位であった ${ }^{14)}$. 今回の結 果からも，喉頭が高位であっても嚥下障害をきたす可能 性が示唆された，喉頭が高位になる理由は，後頭部を支 点とした起始・停止の逆転現象が生じて下顎側に舌骨が 引き寄せられたためと考えられる。ビデオ四燕下造影検査 の際，嚥下時に喉頭挙上範囲が狭いために，十分な気道 防御が困難になる例を経験しているので，今後諸因子を 厳密に検討していきたい．また，燕下障害へのアプロー
チが行われていたにも関わらず悪化した 6 例は, 頸部回 旋と側屈可動域など左右差を表す項目が有意に低く, 日 常生活に扔ける姿勢の影響も含めて, 喉頭位置以外にも 影響を与える因子がないか慎重に検討すべきであると考 える.

\section{3. 不変群の機能変化}

不変群については, 有意な指標変化が生じなかった. このことは，今回使用したこれらの指標が燕下重症度を よく反映しており，その他の運動機能変化に左右されな いことから, 嚥下障害の臨床的指標としてその有用性が 高いことが間接的に明らかになったと考える.しかし， この群に属するケースの中には, 嚥下へのアプローチを 行ったことで鱟下機能を低下させずに維持できたと考え られるケースと，燕下へのアプローチを行ったにもかか わらず, 何らかの原因で変化が生じなかったケースが混 在していることが考えられる。改善を阻害する因子とし ては, 元来, 健常な時からの特異的姿勢や, それによる 臙下器官のアライメント異常などの個別な身体的特徵も 影響しているのではないかと推測している. 今後はこれ らの指標を用いて，燕下運動障害を引き起こしやすい個 別的身体要因についても検証していきたいと考えてい る.

\section{4. 今後の展望}

今回の結果から, 嚥下障害悪化の危険因子としては, 舌骨上筋機能低下，頸部・体幹機能低下などが挙げられ た。これらの指標に注意を向けながら，どのように予防 的なアプローチを行うことが可能であるかについて検討 していくことが急務であると考える.

\section{文献}

1) Kuhlemeier KV:Epidemiology and dysphagia. Dysphagia $1994 ; 9: 209-217$.

2) Robbins J, Levine RL: Swallowing after unilateral stroke of the cerebral cortex : preliminary experience. Dysphagia $1988 ; 3: 11-17$.

3）吉田 剛：脳卒中患者の嶼下障害に対する臨床的指標の 開発と理学療法効果に関する研究. 群馬大学大学院修士 (保健学) 学位論文 2002, p31-43.

4) Burnett TA, Mann EA, Stoklosa JB, Ludlow CL: Selftriggered functional electrical stimulation during swallowing. J Neurophysiol 2005 ; 94 (6) : 4011-4018.

5）吉田 剛, 内山 靖: 喉頭位置と舌骨上筋群の筋力に関 する臨床的評価指標の開発およびその信頼性と有用性. 日摂食・䜩下リ八会誌 $2003 ; 7$ (2) : 143-150.

6) Stambolis V, Brady S, Klos D, Wesling M, Fatianov T, Hildner $\mathrm{C}$ : The effects of cervical bracing upon swallowing in young, normal, healthy volunteers. Dysphagia $2003 ; 18(1): 39-45$.

7) Mann G, Hankey GJ, Cameron D:Swallowing Function 
After Stroke:Prognosis and prognotic factors at 6 months. Stroke 1999 ; 30 : 744-748.

8) Smithard DG, O'Neill PA, England RE, Park CL, Wyatt $\mathrm{R}$, Martin DF, et al. : The natural history of dysphagia following a stroke. Dysphagia $1998 ; 13$ (4) : 188-193.

9) 才藤栄一：摂食能力の減退に対する診断方法の開発. 平 成 7 年度厚生省 - 健康政策調查研究事業分担研究報告書 （個人の摂食能力に応じた「味わい」のある食事内容・ 指導等に関する研究), 1996, p43-52.

10) Tohara H, Saitoh E, Mays KA, Kuhlemeier K, Palmer JB : Three tests for predicting aspiration without videofluorography. Dysphagia $2003 ; 18$ (2) : 126-134.

11）馬場 尊, 才藤栄一：摂食・䱏下障害に対するリハビリ
テーションの適応．臨床リハ 2000;9:857-863.

12）吉尾雅春, 松田淳子, 山下顕史, 澤田三津子, 岡田しげ ひこ：片麻痺の頸・体幹・骨盤の運動機能検査法の改 良. 理学療法学 $1995 ; 22 \mathrm{~S}: 296$.

13) Shaw DW, Cook IJ, Gabb M, Holloway RH, Simula ME, Panagopoulos V, et al. : Influence of normal aging on oralpharyngeal and upper esophageal sphincter function during swallowing. Am J Physiol 1995 ; 268 : G389-396.

14) Yoshida $T$, Uchiyama $Y$ : Clinical characteristics of swallowing disorders caused by cerebrovascular disease. JJPTA 2007 (in press).

\title{
Relationships of swallowing function to changes in motor functions in stroke patients with motor dysphagia
}

\author{
Tsuyoshi Yoshida ${ }^{122)}$ and Yasushi Uchiyama ${ }^{2)}$
}

\begin{abstract}
Aim: To clarify the clinical features of physical therapy for motor dysphagia by identifying changes in indices when swallowing function changes.

Method: Subjects comprised 59 stroke patients with motor dysphagia. They were subdivided into 3 groups according to changes in swallowing function (Group A: improved, Group B: deteriorated, Group C: unchanged). Measured indices for swallowing movement consisted of 4 items; distance from the genion to the thyroid cartilage (GT), distance from the thyroid cartilage to the sternum (TS), relative thyroid position (GT/(GT + TS) ), and strength of the suprahyoid muscles (GS grade). Measured indices for neck-trunk function consisted of the passive neck range of motion in 4 directions (flexion, extension, lateral flexion, and rotation), and neck-trunk-pelvis stage (NTP stage) as described by Yoshio. Measured indices for swallowing function were the repetitive saliva swallowing test, the modified water swallowing test, the food test, and Saitoh's classification of dysphagia.

Results: Group A consisted of 30 patients (mean age, 68.1 years), Group B consisted of 6 patients (mean age, 78.7 years), Group C consisted of 23 patients (mean age, 73.0 years). Group A exhibited significant improvements in GS grade, NTP stage, neck extension and rotation. In Group B, only relative thyroid position was affected. In Group C, no changes were evident.

Conclusion: To obtain improved swallowing function, approaches aimed at both local function of swallowing muscles and neck-trunk function should be used. Preventing deterioration of swallowing function requires attention to thyroid position affected by inappropriate posture.
\end{abstract}

Key words: Dysphagia, Cerebrovascular disease, Swallowing function, Motor function (Jpn J Geriat 2006; 43: 755-760)

1) Department of Rehabilitation, Motojima General Hospital

2) Department of Physical Therapy, Faculty of Medicine, Gunma University 